Bacterial identification systematically failed when using phenotypic methods. Since its implementation in routine laboratory tests, MALDI-TOF mass spectrometry has correctly identified $D$. tsuruhatensis in 4 of 8 tested isolates. For the 4 other isolates, $D$. tsuruhatensis was misidentified as $D$. acidovorans in 3 cases. Accurate identification was definitively performed using $16 \mathrm{~S}$ rDNA sequencing.

In conclusion, $D$. tsuruhatensis is an opportunistic emergent healthcare-associated pathogen that can be easily misidentified. Clinicians should consider this bacterium particularly in immunocompromised patients and those with intravascular devices.

\section{Acknowledgments}

We thank Jacques Albanese and Michel Tsimaratos for their valuable help for retrieving clinical data from additional patients.

This study was supported by Méditerranée Infection and the National Research Agency under the program Investissements d'avenir, reference ANR-10-IAHU-03.

\section{About the Author}

Dr. Ranc is completing his internship in hematology at Nîmes Hospital, France. His current research interest is in modeling hemostasis.

\section{References}

1. Shigematsu T, Yumihara K, Ueda Y, Numaguchi M, Morimura S, Kida K. Delftia tsuruhatensis sp. nov., a terephthalate-assimilating bacterium isolated from activated sludge. Int J Syst Evol Microbiol. 2003;53:1479-83. http://dx.doi.org/10.1099/ijs.0.02285-0

2. Juárez-Jiménez B, Manzanera M, Rodelas B, Martínez-Toledo MV, Gonzalez-López J, Crognale S, et al. Metabolic characterization of a strain (BM90) of Delftia tsuruhatensis showing highly diversified capacity to degrade low molecular weight phenols. Biodegradation. 2010;21:475-89. http://dx.doi.org/10.1007/s10532-009-9317-4

3. Han J, Sun L, Dong X, Cai Z, Sun X, Yang H, et al. Characterization of a novel plant growth-promoting bacteria strain Delftia tsuruhatensis HR4 both as a diazotroph and a potential biocontrol agent against various plant pathogens. Syst Appl Microbiol. 2005;28:66-76. http://dx.doi.org/10.1016/ j.syapm.2004.09.003

4. Tabak O, Mete B, Aydin S, Mandel NM, Otlu B, Ozaras R, et al. Port-related Delftia tsuruhatensis bacteremia in a patient with breast cancer. New Microbiol. 2013;36:199-201.

5. Preiswerk B, Ullrich S, Speich R, Bloemberg GV, Hombach M. Human infection with Delftia tsuruhatensis isolated from a central venous catheter. J Med Microbiol. 2011;60:246-8. http://dx.doi.org/10.1099/jmm.0.021238-0

6. Dubourg G, Abat C, Rolain JM, Raoult D. Correlation between sputum and bronchoalveolar lavage fluid cultures. J Clin Microbiol. 2015;53:994-6. http://dx.doi.org/10.1128/JCM.02918-14

7. Seng P, Drancourt M, Gouriet F, La Scola B, Fournier PE, Rolain JM, et al. Ongoing revolution in bacteriology: routine identification of bacteria by matrix-assisted laser desorption ionization time-of-flight mass spectrometry. Clin Infect Dis. 2009; 49:543-51. http://dx.doi.org/10.1086/600885

8. Drancourt M, Berger P, Raoult D. Systematic 16S rRNA gene sequencing of atypical clinical isolates identified 27 new bacterial

species associated with humans. J Clin Microbiol. 2004;42:2197202. http://dx.doi.org/10.1128/JCM.42.5.2197-2202.2004

9. European Committee on Antimicrobial Susceptibility Testing. Clinical breakpoints: breakpoint tables for bacteria [cited 2016 Jun 6]. http://www.eucast.org/clinical_breakpoints/

Address for correspondence: Florence Fenollar, Unité de Recherche sur les Maladies Infectieuses et Tropicales Emergentes, UMR CNRS 7278, IRD 198, INSERM U1095, Faculté de Médecine, 19-21 Bd Jean Moulin, 13385 Marseille CEDEX 5, France; email: florence.fenollar@univ-amu.fr

\title{
Mycobacterium avium subsp. hominissuis Infection in a Domestic Rabbit, Germany
}

\section{Daniela Klotz, Stefanie A. Barth, Wolfgang Baumgärtner, Marion Hewicker-Trautwein}

Author affiliations: University of Veterinary Medicine, Hannover, Germany (D. Klotz, W. Baumgärtner, M. Hewicker-Trautwein); Friedrich-Loeffler-Institut/Federal Research Institute for Animal Health, Institute of Molecular Pathogenesis, Jena, Germany (S.A. Barth)

DOI: https://doi.org/10.3201/eid2403.171692

Mycobacterium avium subsp. hominissuis is an opportunistic pathogen present in soil and dust. We report $M$. avium subsp. hominissuis infection found in a domestic rabbit in Hannover, Germany, in May 2017.

$M$ ycobacterium avium subsp. hominissuis is an opportunistic pathogen with zoonotic potential $(1,2)$ that is present in soil and dust. Animals are seen as a reservoir and potential threat for human infection, but the route and source of human infection remains unknown in most cases (3-6). We report on a 4-year-old intact male rabbit from a private breeder in Germany that died suddenly in May 2017. Several months before death, the rabbit showed intermittent diarrhea, and the veterinarian suspected coccidiosis. Necropsy findings included cachexia with small amounts of a clear fluid in body cavities due to hypoproteinemia; dehydration; multifocal intramural nodules $\leq 4 \mathrm{~mm}$ in diameter in the jejunum and ileum; highly liquefied intestinal contents without molding; and enlarged mesenteric lymph nodes. We detected single coccidia parasites in a native intestinal smear. Histologically, the nodular lesions in the ileum 
Figure. Results of histologic testing of samples from a domestic rabbit with Mycobacterium avium subsp. hominissuis infection, Germany. A) Hematoxylin and eosin stain reveals multifocal severe granulomatous enteritis in the ileum with focally extensive necrosis (asterisk) and numerous surrounding macrophages (arrowhead). Scale bar indicates $300 \mu \mathrm{m}$. B) Ziehl-Neelsen stain shows numerous acid-fast bacilli in the cytoplasm of macrophages and multinucleated giant cells (arrowheads). Scale bar indicates $20 \mu \mathrm{m}$.

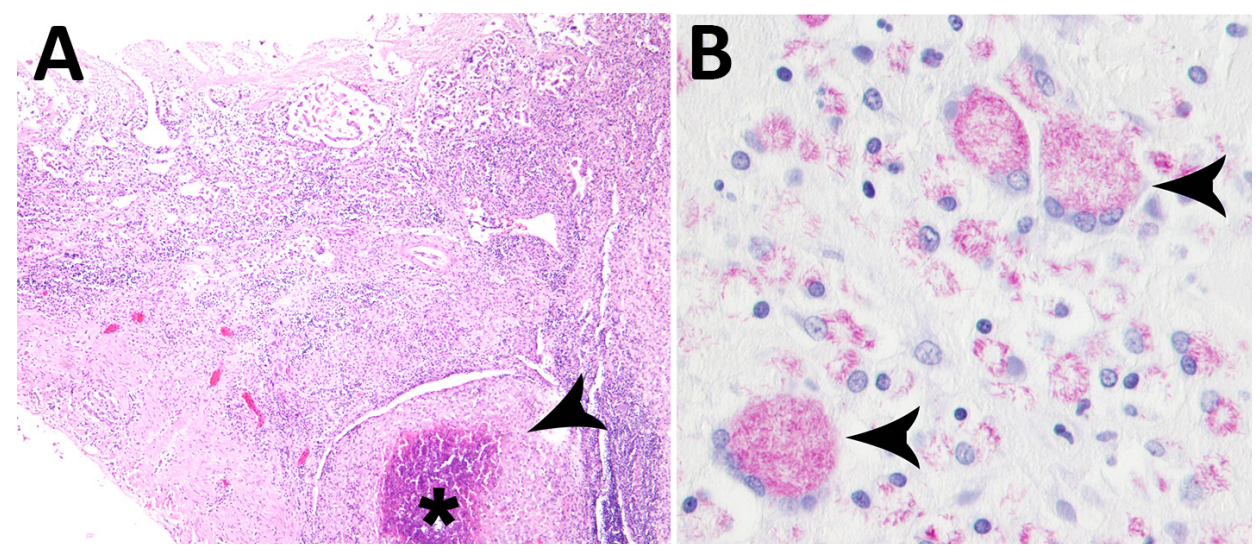

showed severe granulomatous enteritis with large areas of necrosis and numerous multinucleated giant cells (Figure, panel A). Ziehl-Neelsen stain demonstrated large numbers of acid-fast bacilli in macrophages and multinucleated giant cells in the intestine (Figure, panel B). The mesenteric lymph node also exhibited a granulomatous inflammation with multinucleated giant cells. Additionally, the rabbit had mild suppurative splenitis, mild lymphohistiocytic to granulomatous hepatitis, mild focal lymphocytic interstitial orchitis, and a hyperplasia of the myeloic cell line in the femoral and sternal bone marrow. We detected no acid-fast bacilli in the mesenteric lymph nodes, the spleen, or the liver.

We decontaminated sections of the small intestine using NALC-NaOH and cultivated on Löwenstein-Jensen (Artelt-Enclit GmbH, Germany), Stonebrink (Artelt-Enclit), and Herrold's Egg Yolk (Becton Dickinson GmbH, Germany) agar slants (the last supplemented with Mycobactin J), as well as in Kirchner medium (Artelt-Enclit). We extracted DNA from grown colonies after heat inactivation by ultrasonic cell lysis and analyzed the DNA by PCRs targeting insertion sequence (IS) 1245, IS900, and IS901. The presence of IS1245-specific and absence of IS900- and IS901-specific PCR products identified the bacilli as $M y$ cobacterium avium subsp. hominissuis. Additionally, DNA sequencing of a $r p o B$ gene PCR fragment yielded $100 \%$ sequence identity to rpoB from $M$. avium $\mathrm{ssp}$. hominissuis strain IWGMT49 (GenBank accession no. EF521911) (7).

M. avium subsp. hominissuis is not currently a reported pathogen for rabbits. It has been reported only once in a slaughtered rabbit, but that animal showed no clinical or pathological abnormalities (8). In our investigation, as in reports in other host species, the source and route of infection was unclear. The presence of enteric inflammatory lesions with presence of acid-fast bacilli, however, suggests an oral route of infection.

It has been reported that a mycobacterial infection is dependent on the immunity and nutritional status of the host $(2,9)$. In this case, the infestation with coccidia, common intestinal parasites in rabbits that can cause emaciation, may have contributed to the massive mycobacterial infection. Nevertheless, clinically manifest mycobacterial infection is a rare finding in domestic rabbits. We encourage awareness of a potential zoonosis, such as infection with $M$. avium subsp. hominissuis, in rabbits with intermittent diarrhea and chronic weight loss.

\section{Acknowledgments}

We thank Caroline Schütz, Claudia Herrmann, Christiane Namneck, and Uta Brommer for their excellent technical assistance.

\section{About the Author \\ Ms. Klotz is a veterinarian and postgraduate doctoral student in the Department of Pathology, University of Veterinary Medicine, Hannover, since 2014. Additionally, she participates in the training for the certifying examination of the European College of Veterinary Pathologists.}

\section{References}

1. Slany M, Ulmann V, Slana I. Avian mycobacteriosis: still existing threat to humans. BioMed Res Int. 2016;2016:4387461. http://dx.doi.org/10.1155/2016/4387461

2. Tortoli E. Clinical manifestations of nontuberculous mycobacteria infections. Clin Microbiol Infect. 2009;15:906-10. http://dx.doi.org/10.1111/j.1469-0691.2009.03014.x

3. Lahiri A, Kneisel J, Kloster I, Kamal E, Lewin A. Abundance of Mycobacterium avium ssp. hominissuis in soil and dust in Germany-implications for the infection route. Lett Appl Microbiol. 2014;59:65-70. http://dx.doi.org/10.1111/lam.12243

4. Haist V, Seehusen F, Moser I, Hotzel H, Deschl U, Baumgärtner W, et al. Mycobacterium avium subsp. hominissuis infection in 2 pet dogs, Germany. Emerg Infect Dis. 2008;14:988-90. http://dx.doi.org/10.3201/eid1406.071463

5. Kriz P, Jahn P, Bezdekova B, Blahutkova M, Mrlik V, Slana I, et al. Mycobacterium avium subsp. hominissuis infection in horses. Emerg Infect Dis. 2010;16:1328-9. http://dx.doi.org/10.3201/ eid1608.100097

6. Shitaye EJ, Grymova V, Grym M, Halouzka R, Horvathova A, Moravkova M, et al. Mycobacterium avium subsp. hominissuis infection in a pet parrot. Emerg Infect Dis. 2009;15:617-9. http://dx.doi.org/10.3201/eid1504.081003 
7. Ben Salah I, Adékambi T, Raoult D, Drancourt M. rpoB sequencebased identification of Mycobacterium avium complex species. Microbiology. 2008;154:3715-23. http://dx.doi.org/10.1099/ mic. $0.2008 / 020164-0$

8. Arrazuria R, Sevilla IA, Molina E, Pérez V, Garrido JM, Juste RA, et al. Detection of Mycobacterium avium subspecies in the gutassociated lymphoid tissue of slaughtered rabbits. BMC Vet Res. 2015;11:130. http://dx.doi.org/10.1186/ s12917-015-0445-2

9. Gupta KB, Gupta R, Atreja A, Verma M, Vishvkarma S. Tuberculosis and nutrition. Lung India. 2009;26:9-16. http://dx.doi.org/10.4103/0970-2113.45198

Address for correspondence: Marion Hewicker-Trautwein, University of Veterinary Medicine Hannover, Department of Pathology, Bünteweg 17, 30559 Hannover, Germany; email: Marion.Hewicker-Trautwein@tiho-hannover.de

\section{Acetobacter indonesiensis Pneumonia after Lung Transplantation}

\author{
Sankha S. Basu, Mary L. Delaney, Ning Li, \\ Andrew B. Onderdonk, Lynn Bry
}

Author affiliation: Brigham and Women's Hospital, Boston, Massachusetts, USA

DOI: https://doi.org/10.3201/eid2403.170409

We report a case of Acetobacter indonesiensis pneumonia in a 51 -year-old woman after bilateral lung transplantation. We found 2 other $A$. indonesiensis pneumonia cases reported in the literature. All 3 cases involved complex patients exposed to broad-spectrum antimicrobial drugs, suggesting that this pathogen may be opportunistic and highly drug-resistant.

\footnotetext{
$A^{s}$ 51-year-old woman who had a medical history of hyperensitivity pneumonitis, extrinsic allergic alveolitis, and short telomere syndrome was admitted to a local hospital in Massachusetts, USA, for hypoxemic respiratory failure. The patient was transferred to the tertiary care hospital in which we practice in Boston, where she ultimately underwent a bilateral lung transplant from a high-risk donor without induction immunosuppression. The donor lungs grew group C Streptococcus, Peptostreptococcus micros, and Candida albicans. The native lungs were culture-negative.
}

The patient's postoperative hospital course was complicated by fever, leukocytosis, anemia, thrombocytopenia, and acute kidney injury. The clinical treatment team treated the patient with trimethoprim/sulfamethoxazole (TMP/SMX) and vancomycin; the latter was discontinued and piperacillin/tazobactam (14 days total) was administered after identification of $P$. micros in the donor's lungs. On postoperative day 21, 4 days after completion of her antimicrobial drug therapy, the patient continued to have respiratory symptoms, and we cultured samples from a tracheostomy suction. A Gram stain of the tracheostomy suction fluid revealed gram-variable coccobacilli. The next day, we also found 2 bronchioalveolar lavage specimens to be positive for gramvariable coccobacilli and considered them to be of the same phenotype. The patient's symptoms, along with the presence of the organism in 3 separate and sequential samples, argued against contamination.

Standard microbiological culture techniques revealed a slow-growing organism that was catalase-positive, oxidase-negative, L-pyrrolidonyl- $\beta$-napthylamide hydrolysisnegative, and vancomycin-resistant. We did not identify the organism by using exhaustive phenotypic techniques. We sequenced 16S rRNA (online Technical Appendix Table, https://wwwnc.cdc.gov/EID/article/24/3/17-0409Techapp1.pdf) and identified the organism as Acetobacter indonesiensis; we deposited this sequence in GenBank (accession no. KP330469). Because of the rare occurrence of this pathogen in humans $(1,2)$, we achieved additional biochemical testing by using short- and medium-chain fatty acid analysis, which provided additional evidence supporting sequence-based identification.

At the time of the infection, the clinical microbiology laboratory at our hospital was not equipped with a matrixassisted laser desorption/ionization time-of-flight mass spectrometry bacterial identification platform. However, this organism is not in any Food and Drug Administration-approved databases and therefore would not have been identified by using this instrumentation. Antimicrobial drug susceptibility testing using disk diffusion revealed an organism that failed to demonstrate in vitro activity to ampicillin, levofloxacin, ciprofloxacin, cephalothin, cefotetan, ceftadazime, cefepime, chloramphenicol, ertapenem, meropenem, piperacillin, aztreonam, thiosulfil/sulfamethizole, TMP/SMX, or colistin. The isolate did, however, demonstrate in vitro activity against aminoglycosides, tetracyclines, imipenem, and ceftriaxone. This drug susceptibility profile was similar to the profile found against the $A$. indonesiensis organism identified in a previously reported case (2).

Although this patient's isolate was resistant to the antimicrobial drugs she had received, her symptoms ultimately resolved. On postoperative day 33 , her respiratory function had improved, and she was prescribed TMP/SMX (prophylaxis) and fluconazole at discharge. 